\title{
Vein of Galen malformation
}

\author{
Stanley Hoang, B.S., Omar Choudhri, M.D., Michael Edwards, M.D., \\ and Raphael GuZman, M.D.
}

Department of Neurosurgery, Division of Pediatric Neurosurgery, Lucile Packard Children's Hospital, Stanford University School of Medicine, Stanford, California

\begin{abstract}
A vein of Galen malformation is a rare intracranial vascular lesion affecting the pediatric population. Its poor prognosis has been significantly improved with the development of endovascular embolization. In this paper the authors review the developmental mechanisms, clinical pathophysiology, and the available data on the management and outcome of the disease. (DOI: 10.3171/2009.8.FOCUS09168)
\end{abstract}

$\begin{array}{lll}\text { KEY WORDS } & \text { vein of Galen malformation } & \bullet \quad \text { endovascular embolization } \\ \text { outcome } & \text { review }\end{array}$

A VGM consists of multiple arteriovenous shunts draining into a dilated median prosencephalic

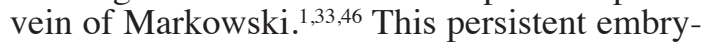
onic vein is normally absent in the adult. Although a rare intracranial vascular anomaly, VGM has been estimated to represent $30 \%$ of pediatric vascular malformations. ${ }^{32}$

\section{Review of VGMs}

Although the etiological basis of VGM remains to be elucidated, its developmental embryology is intertwined with the development of the cerebral vascular system, which occurs in three stages. ${ }^{42}$ In prechoroidal Stage I, neural cells organized around the neural tube receive nutrients from direct diffusion of the amniotic fluid. ${ }^{13}$ In prechoroidal Stage II, the thickened neural mantle receives vascular channels from the meninx primitiva. In the choroidal stage, after closure of the anterior and posterior neuropores, the developing brain is supplied principally by the choroid plexuses and drained by the large median prosencephalic vein of Markowski ${ }^{13}$ Later, paralleled with the maturation of the cortical arterial network replacing the choroidal arteries, internal cerebral veins develop and drain into the median prosencephalic vein of Markowski, which gradually involutes and eventually persists as the great cerebral vein, or vein of Galen. ${ }^{13}$ In patients with VGM, arteriovenous shunts, with their arterial supply largely derived from choroidal arteries, for unknown reasons, develop between the 6th and 11th weeks of intrauterine life. ${ }^{43}$ The high blood flow from inadequate

Abbreviations used in this paper: $\mathrm{VGAD}=$ vein of Galen aneurysmal dilation; VGM = vein of Galen malformation. capillary resistance, likely coupled with accompanying dural sinus stenoses, causes the anterior segment of the median prosencephalic vein of Markowski, which normally regresses, to instead progressively enlarge and to form the aneurysmal component of a typical VGM..$^{13,37}$

\section{Classification of the Malformation}

The angioarchitecture of VGM can be classified into the mural or choroidal type, depending on the characteristic of the fistula. ${ }^{15,49}$ The mural type consists of high-flow shunts, supplied by the collicular and posterior choroidal arteries, ending directly within the aneurysmal wall of the median prosencephalic vein. The choroidal type involves the interposition of an extensive arterial network between the arterial feeder, supplied by the choroidal, subfornical, or pericallosal arteries or thalamoperforator arteries, and the venous aneurysm..$^{13}$ The choroidal form usually leads to more severe symptoms whereas the mural form is better tolerated clinically. ${ }^{2}$ Mixed forms combining direct shunts and arterial networks may also occur.

Vein of Galen malformations should be differentiated from the VGAD, which represents a normally formed vein of Galen that dilates as a result of outflow obstruction (Fig. 1). ${ }^{20}$ The dilated venous structure drains an arteriovenous malformation located in the subarachnoid space, either supra- or infratentorially, in addition to the adjacent normal cerebral parenchyma..$^{2,15}$ The degree of dilation is variable and depends on the extent of stenoses or thrombosis. The frequency of VGADs in neonates and infants is low and patients with VGAD often present in later age during childhood, with intracranial hemorrhage, focal neurological deficits, and in the very young, with delayed psychomotor development. ${ }^{23}$ With VGAD, epi- 


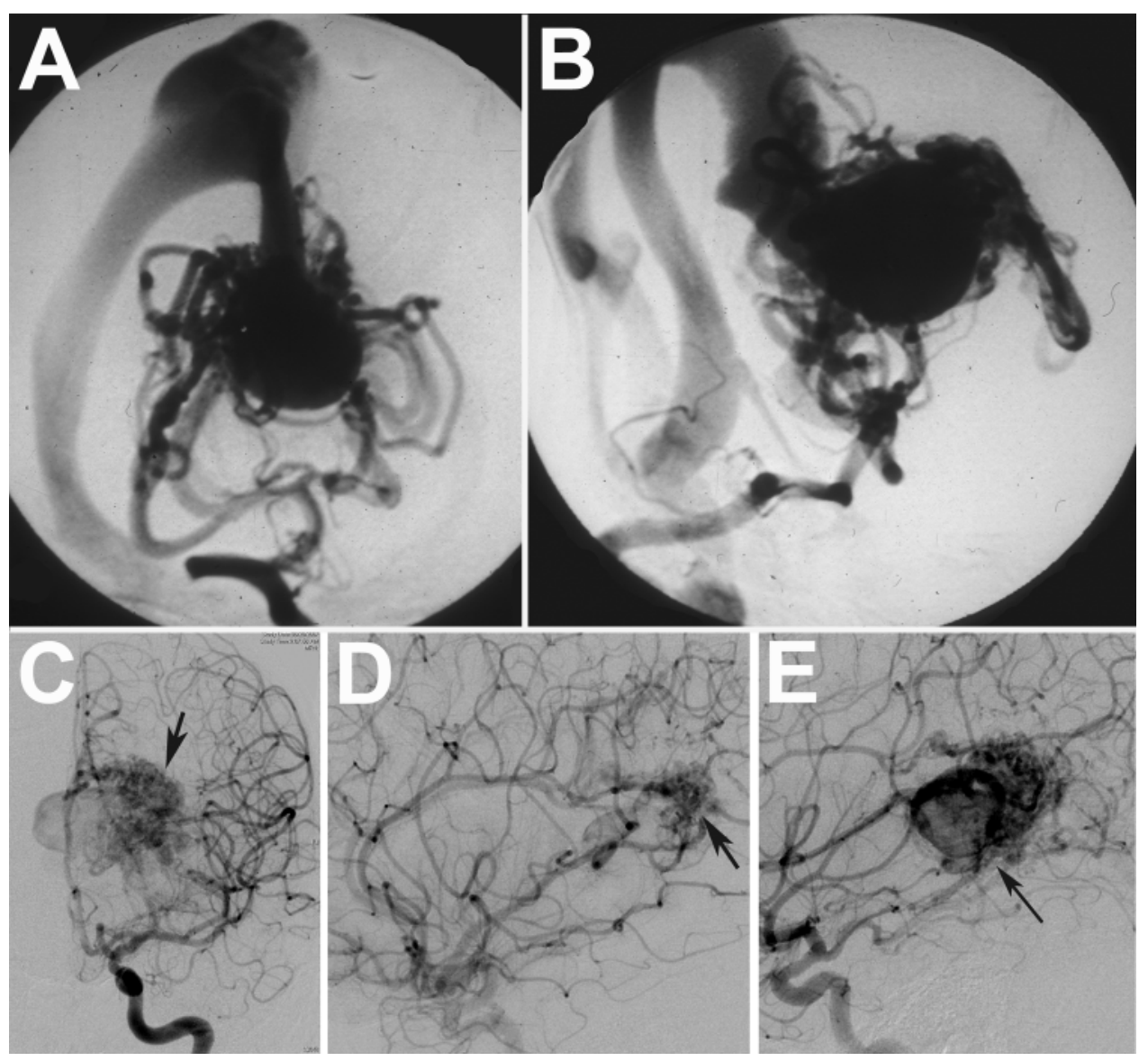

FIG. 1. Angiographic differences between a true VGM (A and B) and a dilated vein of Galen (VGAD) with an arteriovenous malformation (C-E). A and B: Mural-type VGM with fistulas ending in the aneurysmal wall of the median prosencephalic vein (anteroposterior view $[\mathrm{A}]$ and oblique view $[\mathrm{B}]$ ) in a newborn with congestive heart failure. C-E: Arteriovenous malformation (arrows in $\mathrm{C}$ and $\mathrm{D}$ ) draining into a VGAD (arrow in $\mathrm{E}$ ) in a 13-year-old patient presenting with intraventricular hemorrhage.

lepsy is not common, because of the deep location of the lesions, and heart failure is also uncommon because of its presentation in older children. ${ }^{2}$

\section{Pathophysiological Characteristics}

The pathophysiological consequences of VGM most often manifests as high-output cardiac failure and neurological symptoms secondary to cerebral venous congestion and abnormal CSF flow. ${ }^{2}$ The severity of the symptoms is variable and dependent on the underlying angioarchitecture of the VGM as well as the age of the child. Typically neonates present with congestive heart failure, infants present with hydrocephalus, and the older children or adults present with headache and, frequently, with signs and symptoms of subarachnoid hemorrhage.

\section{Cardiac and Systemic Manifestations}

Cerebral low-resistance arteriovenous shunts in VGM lead to increased venous return to the right atrium, subsequent pulmonary hypertension due to increased pulmonary blood flow, and ultimately congestive heart failure as a result of the increased preload. 2,6 Although the VGM develops in utero, it does not produce severe cardiac failure until after the child is born. The low resistance in the placenta competes with the VGM, and therefore the flow through the malformation is not as great in the fetus as it is after birth. After birth and removal of the placenta, flow through the fistula suddenly increases. Large arteriovenous shunts reduce the diastolic pressure within the aorta, leading to reduced coronary blood flow, which, coupled with the high ventricular pressure, can promote myocardial ischemia. ${ }^{20,41}$ Flow reversal in the aorta can lead to renal hypoperfusion and subsequently to renal failure. Congestive heart failure developed prenatally can be detected on ultrasound and in severe cases can lead to multiorgan failure and irreversible brain damage., ${ }^{2,6}$ While antenatal diagnosis is not an indication for abortion or early or cesarian delivery, in utero cardiac failure and brain damage represent indications for abortion. ${ }^{31}$

In the neonatal period, cardiac symptoms may range from mild volume overload to severe cardiogenic shock depending on the maturity of the cardiopulmonary system. ${ }^{2,9,14,44}$ Mild symptoms can consist of feeding difficulties, tachycardia, and signs of cardiomegaly on chest radiography. ${ }^{2}$ In the mild condition, diuretics can be used to improve symptoms, permit normal feeding, and allow the patient to return in 5 months for embolization procedure. ${ }^{2}$ In severe cases, the patient may require mechanical 


\section{Vein of Galen malformations}

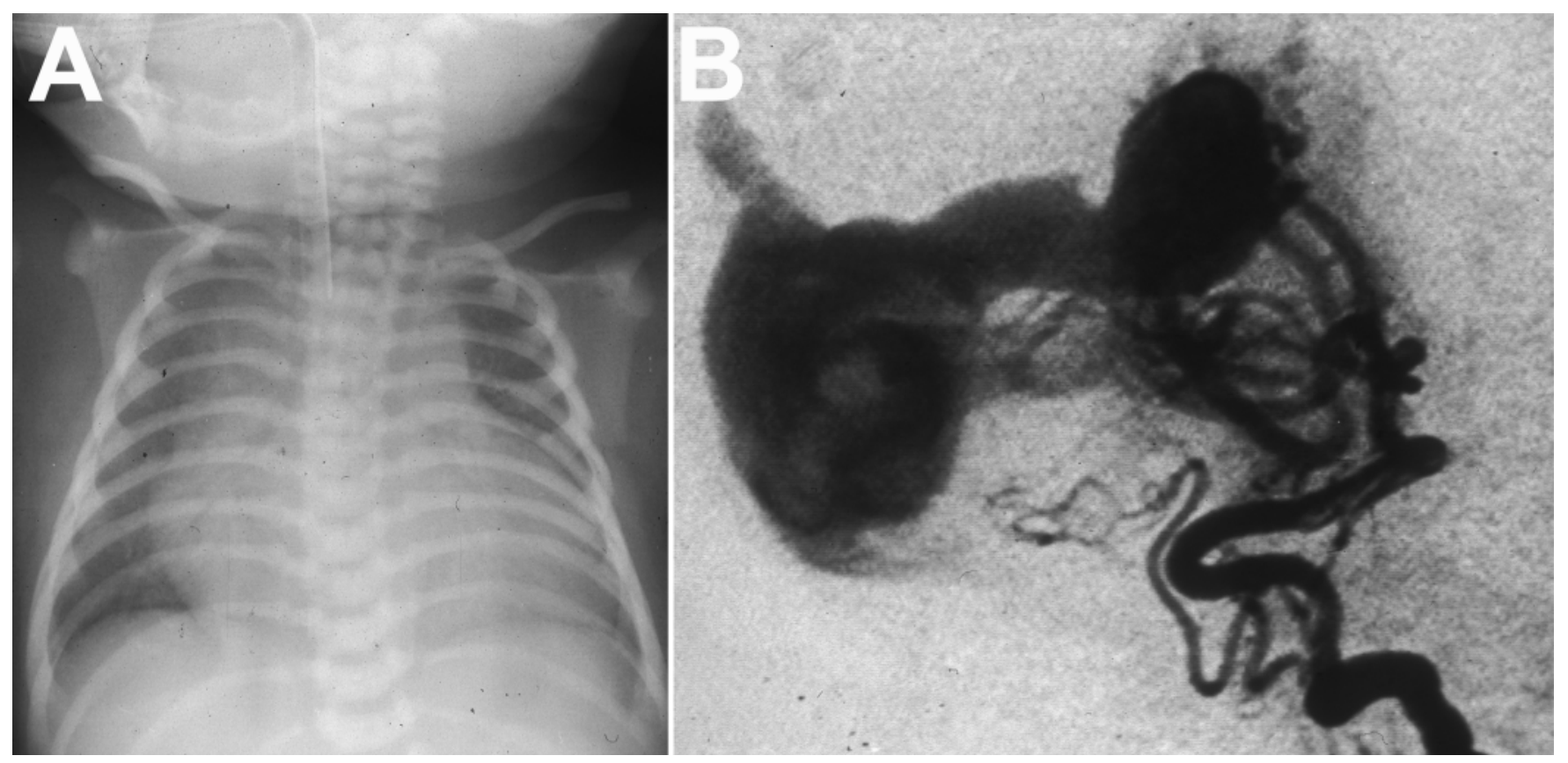

FiG. 2. The increased venous return to the right atrium can lead to pulmonary hypertension and ultimately congestive heart failure as a result of the increased preload. A: Anteroposterior chest radiograph obtained in a newborn with congestive heart failure showing cardiomegaly. B: Angiogram demonstrating the VGM.

ventilation, together with diuretics and inotropic medications, and in refractory cases, may require immediate embolization of the cerebral arteriovenous shunts. ${ }^{2}$

In contrast to prenatal patients and neonates, infants rarely present with symptoms of congestive heart failure. They can be treated with diuretics until embolization and can be frequently weaned from these medications after the first embolization procedure. ${ }^{2}$

\section{Neurological Manifestations}

Because of the tremendous flow of blood to the fistula, the blood is stolen from the cerebral parenchyma, leading to ischemic damage. High blood flow in the arteriovenous shunt and reduction in venous drainage secondary to poorly developed venous system or venous stenosis, coupled with altered hemodynamics due to cardiac manifestations, can result in high cerebral venous pressure and cerebral edema. ${ }^{20}$ Together these manifestations can lead to a rapid loss of brain tissue in the neonatal period, the most severe form referred to as the melting brain. $^{2}$ The high venous pressure, coupled with the lack of maturation of the arachnoid granulations, can lead to impaired CSF resorption, resulting in hydrocephalus. ${ }^{20,50}$ Obstructive hydrocephalus can also occur due to VGMinduced compression of the aqueduct. When hydrocephalus is present before 5 months, embolization should be the first line of treatment leading to a reduction in venous pressure and improvement of CSF resorption. A CSF shunt or ventriculostomy does not correct the underlying problem ${ }^{2}$ and can potentially lead to intracerebral hemorrhage from the congested and immature venous system. Rerouting of blood flow into the facial veins or basilar or pterygoid plexus can lead to prominent facial veins and epistaxis. $^{18,20}$

\section{Clinical Presentation}

In 1964 , Gold et al. ${ }^{17}$ described typical clinical presentations that remain valid today for 3 age groups of patients with VGMs. The clinical pictures are correlated with the age of presentation and the underlying pathophysiology.

Neonates. Symptomatic newborns present with severe cardiorespiratory failure including hydrops and renal failure secondary to flow reversal in the aorta at or shortly after birth. ${ }^{13}$ In one series, in the majority of cases (94\%) diagnosed in the neonatal period, the patients presented with high-output cardiac failure. ${ }^{44}$ Severe pulmonary hypertension may also complicate management. Cyanosis may be present and may thus be mistaken for congenital heart disease. ${ }^{25}$ An electrocardiogram can detect some features of myocardial infarction. ${ }^{14}$ In any infant born with high-output cardiac failure, a VGM should be ruled out. While the mortality rate in the past was close to $100 \%$, recent advances in endovascular techniques have greatly improved the survival rate.

Infancy. In contrast to the neonates, patients presenting during infancy usually have smaller shunts and only mild cardiac manifestations. These patients most frequently present with increased head circumference due to aqueduct compression by a dilated vein of Galen resulting in hydrocephalus or seizures (Fig. 2). ${ }^{13,17,20}$ Those with longstanding cerebral venous hypertension may present with developmental delay. ${ }^{20}$ Some also have failure to thrive resulting from cardiac decompensation or even hypothalamic and hypophyseal dysfunction as a result of venous congestion.,30 Other signs and symptoms often include cranial bruit, dilated scalp veins, proptosis, and occasionally recurrent epistaxis..$^{13}$ 
S. Hoang et al.

TABLE 1: Summary of the Bicêtre neonatal evaluation score*

\begin{tabular}{|c|c|c|c|c|c|}
\hline \multirow[b]{2}{*}{ Scoret } & \multicolumn{5}{|c|}{ Function } \\
\hline & Cardiac & Cerebral & Respiratory & Hepatic & Renal \\
\hline 5 & normal & normal & normal & & \\
\hline 4 & overload \& no med Tx & $\begin{array}{l}\text { subclinical; isolated EEG } \\
\text { abnormalities }\end{array}$ & tachypnea; finishes bottle & & \\
\hline 3 & failure; stable w/ med Tx & $\begin{array}{l}\text { nonconvulsive, intermittent } \\
\text { neurological signs }\end{array}$ & $\begin{array}{l}\text { tachypnea; does not finish } \\
\text { bottle }\end{array}$ & $\begin{array}{l}\text { no hepatomegaly; normal hepatic } \\
\text { function }\end{array}$ & normal \\
\hline 2 & $\begin{array}{l}\text { failure; not stable w/ } \\
\text { med Tx }\end{array}$ & isolated convulsion & $\begin{array}{l}\text { assisted ventilation; normal } \\
\text { saturation } \mathrm{FiO}_{2}<25 \%\end{array}$ & $\begin{array}{l}\text { hepatomegaly; normal hepatic } \\
\text { function }\end{array}$ & $\begin{array}{l}\text { transient } \\
\text { anuria }\end{array}$ \\
\hline 1 & ventilation needed & seizures & $\begin{array}{l}\text { assisted ventilation; normal } \\
\text { saturation } \mathrm{FiO}_{2}>25 \%\end{array}$ & $\begin{array}{l}\text { moderate or transient hepatic } \\
\text { insufficiency }\end{array}$ & $\begin{array}{l}\text { unstable diure- } \\
\text { sis w/ Tx }\end{array}$ \\
\hline 0 & resistant to med Tx & $\begin{array}{l}\text { permanent neurological } \\
\text { signs }\end{array}$ & $\begin{array}{l}\text { assisted ventilation; desatura- } \\
\text { tion }\end{array}$ & $\begin{array}{l}\text { abnormal coagulation, elevated } \\
\text { enzyme levels }\end{array}$ & anuria \\
\hline
\end{tabular}

* Table adapted from Lasjaunias et al., 2006. Abbreviations: $\mathrm{EEG}=$ electroencephalogram; $\mathrm{FiO}_{2}=$ fractional inspired oxygen; med = medical.

$\uparrow$ Maximal score is 21: 5 (cardiac) +5 (cerebral) +5 (respiratory) +3 (hepatic) +3 (renal) .

Older Children and Adults. Older children most often present with headache and seizures caused by intraparenchymal or subarachnoid hemorrhage. ${ }^{2,13,20}$ The VGM is usually small with a limited degree of arteriovenous shunt, but the angiomatous network supplying the vein of Galen can harbor microaneurysms. A vein of Galen dilation secondary to outflow obstruction should also be considered in the differential diagnosis.

\section{Imaging Modalities}

Ultrasound. Ultrasonography is a noninvasive technique for bedside evaluation of the cerebral vascular system that is quick and convenient, although strongly operator dependent..$^{13,46}$ Antenatal ultrasound can show the venous sac located posterior to the third ventricle and can use pulsatile flow within the lesion to differentiate a VGM from other midline cystic structures. ${ }^{20,40,48}$ It can also demonstrate associated venous anomalies, the presence of hydrocephalus, and cardiac dysfunction..$^{20}$ In the postnatal period, ultrasound can be used to assess progressive thrombosis of the venous sac and quantify residual postembolization flow after endovascular therapy. ${ }^{7,45}$ The use of ultrasound and Doppler imaging is also critical to assess flow reversal in the aorta and changes after treatment. Ultrasound is preferred over CT and MR angiography because of MR imaging artifacts due to metal embolization coils, but it may not be sensitive enough to detect slow flow in areas of embolization. ${ }^{37}$

Computed Tomography. Contrast-enhanced axial CT scanning of the brain can demonstrate a multilobulated, intensely enhancing lesion, ventricular dilation, periventricular white matter hypodensities, diffuse cerebral atrophy, and thrombosis within the aneurysm sac. ${ }^{20}$ Computed tomography scanning is also an important modality for demonstrating intracerebral calcifications secondary to ischemic brain damage. Advances in CT angiography and multidetector technology have allowed for greater resolution of the vascular bed. ${ }^{1,24}$ Although not as precise as angiography, CT angiography is a noninvasive tech- nique that offers more detailed vascular information than that of ultrasound or MR imaging and can be performed in awake or slightly sedated patients..$^{13}$ In addition, multislice spiral CT angiography has been found to be very useful for detailed mapping of both arteries and veins, with the use of a single scan and a single dose of contrast medium. ${ }^{16,36}$ It requires fewer than 5 minutes for processing and is faster and with better imaging quality than MR angiography or single-slice CT angiography. When multislice spiral CT angiography is not available, CT angiography is preferred over MR angiography because of greater image quality for cerebral vein identification. ${ }^{37}$

Magnetic Resonance Imaging. Ultrasound now frequently detects VGMs in utero, although MR imaging is increasingly used, not only for the characterization of the lesion but also the documentation of brain atrophy and cardiac abnormalities. ${ }^{4,23,26}$ Magnetic resonance imaging can identify the fistula location, presence of any nidus, venous drainage, venous thrombosis, and it can estimate the number and type of arterial feeders. ${ }^{13,20,39}$ Importantly, because of its exquisite soft-tissue contrast, MR imaging is the modality of choice to evaluate the ventricular system and cerebral parenchymal damage, which is important for therapeutic decision making and prognosis., ${ }^{43}$

Angiography. Angiography is the gold standard for precise evaluation of VGM angioarchitecture, including detailing the anatomy of arterial feeders and the hemodynamics of venous drainage, and it provides access for endovascular management..$^{13}$ If a VGM is diagnosed in utero, it is imperative to preserve the umbilical artery because this will give the best endovascular access in the neonatal period. Catheterization of the umbilical artery is most convenient and can be done up to the 3rd day of life. Femoral access is possible, but the vessel is smaller and it carries the risk of possible limb ischemia. ${ }^{13}$ In newborns with severe VGM and cardiac failure concomitant with renal insufficiency, angiography can be complicated by the limited amount of contrast agent that can be used. In general if the patient is clinically stable, angiography should be delayed until the 5th month of life. ${ }^{27}$ 


\section{Vein of Galen malformations}

TABLE 2: Studies on clinical outcomes following embolization for treatment of VGM

\begin{tabular}{ll}
\hline \multicolumn{1}{c}{ Authors \& Year } & Outcome \\
\hline $\begin{array}{l}\text { Mickle \& Quisling, 1986 } \\
\text { Friedman et al., 1993 }\end{array}$ & $\begin{array}{l}\text { authors used transtorcular embolization of the VGM using Gianturco coils in } 3 \text { pts; satisfactory outcome in } 2 \text { pts } \\
\text { improved embolization techniques decreased the mortality rate from 50\% (w/ 22 neonates) in 1991 to 0\% (11 neonates) in } \\
1993 \\
\text { Fullerton et al., 2003 }\end{array}$ \\
$\begin{array}{l}\text { Gupta et al., 2006 } \\
\text { embolization in 27 pts resulted in 61\% having no or mild developmental delay \& a 15\% mortality rate during hospitalization } \\
\text { Lasjaunias et al., 2006 }\end{array}$ & $\begin{array}{l}\text { endovascular embolization in 233 pts resulted in angiographically confirmed } 90-100 \% \text { occlusion in 55\% of pts; mortality } \\
\text { rate 10.6\%; 74\% of survivors neurologically normal on follow-up }\end{array}$ \\
\hline
\end{tabular}

\section{Management}

The development of endovascular therapy, together with a comprehensive multidisciplinary approach in the intensive care units, has significantly improved the poor prognosis of patients with VGM. ${ }^{13,19,31}$ Despite advances in microneurosurgery, complete removal of the lesion in newborns is rarely achieved or advised, because of the hemodynamic instability and location of the lesion, poor myelination of the brain parenchyma, and cerebral venous hypertension. As a result, surgical treatment is now reserved for the evacuation of intracranial hematomas and the treatment of hydrocephalus, or in cases of embolization failure. Medical treatment with diuretics, inotropes, and other cardiovascular agents is used only to relieve symptoms of cardiovascular instability and renal insufficiency until the patient can undergo embolization. ${ }^{15}$ Most of the newborns with VGM need immediate treatment. The main goal in the newborn with high-output cardiac failure is to decrease the flow in the VGM and therefore reduce the cardiac output failure, improve the coronary perfusion, and increase the blood flow to the renal arteries. If a patient has persistent or recurrent heart failure and cyanosis after initial successful endovascular treatment, a persistent patent ductus arteriosus has to be ruled out. The pathological hemodynamic situation with increased venous return to the right side of the heart and right-to-left shunting through a patent foramen ovale can lead to a failure of the ductus arteriosus to close requiring treatment.

Endovascular Treatment. Endovascular access can be gained via the transarterial or transvenous route..$^{13}$ In the newborn arterial access can be achieved through the umbilical artery if patent or through the femoral artery. The embolic glue of choice to occlude the arteriovenous fistula on the arterial side is $N$-butyl-cyanoacrylate, and more recently Onyx has been used as well. ${ }^{13,22,31}$ Detachable microcoils can also be used, although their application may take longer and they may have a higher risk of vessel rupture. ${ }^{13}$ The transvenous route can be approached via the femoral or jugular vein or alternatively, through direct puncture of the torcula. ${ }^{13,34,35}$ Although some groups have used the venous route with success, ${ }^{5}$ others reserve it for patients in whom the arterial route cannot be approached successfully. ${ }^{13,31}$ In addition, occlusion of the venous aneurysm may hinder deep venous drainage or result in perforation of the venous aneurysm..$^{8,12}$
A patient's clinical presentation dictates the timing of endovascular management. ${ }^{20}$ Congestive heart failure refractory to medical management in a newborn necessitates emergency embolization to relieve the hemodynamic load on the heart. In this case, partial, rather than complete, obliteration of the shunt is the goal to allow for redistribution of blood flow to the heart and brain to allow normal cardiac and neurological development. ${ }^{19}$ The residual shunt can then be occluded at a later time to reduce complications.

In a child who does not present with cardiac failure, the goal is to prevent the development of cerebral venous hypertension. ${ }^{47}$ Treatment often involves multiple successive procedures that target different pedicles to avoid parenchymal bleeding and venous thrombosis. ${ }^{13}$ Ideally, if the patient is not in heart failure, treatment should be deferred until 5-6 months of age, when fluid hemodynamics are still amenable to change and there is a low risk of affecting brain maturation. 13,20,38 However, excessive delay may lead to permanent neurological and cardiac impairment unsalvageable by intervention. Spontaneous thrombosis is a rare event $(2.5 \%$ in a recent series of 317 patients ${ }^{31}$ ) and should not be relied on to delay intervention. ${ }^{13}$ Recently, Lasjaunias et al. ${ }^{31}$ described a 21-point scale score based on cardiac, cerebral, hepatic, respiratory, and renal function to guide therapeutic decisions (Table 1). A score of $<8$ often signifies a poor prognosis that does not warrant treatment, a score from 8 to 12 is an indication for emergency embolization, and a score of $>12$ indicates medical management until the child is at least 5 months of age.

\section{Complication and Prognosis}

Before the development of endovascular embolization, a newborn with a VGM had a dismal prognosis. In 1964, Gold et al. ${ }^{17}$ reported a $100 \%$ mortality rate in 9 neonates. Hoffman et al. ${ }^{21}$ also reported an intraoperative mortality rate of $99-100 \%$. In the initial personal surgical experience of the coauthor (M.E.), the mortality rate was $100 \%$. Endovascular techniques, together with improvement in perinatal management, have significantly improved outcomes by mitigating the effects of cardiovascular complications (Table 2). Reporting their early experience in 1993 with endovascular embolization, Friedman et al. ${ }^{10}$ noted an improvement in the mortality rate from $50 \%$ (22 neonates) in 1991 to $0 \%$ in 1993 (11 neonates) as a result of improvements in embolization 


\section{S. Hoang et al.}

techniques. In 1996, Lasjaunias et al. ${ }^{28}$ reported a mortality rate of $9 \%$ in 78 patients, while $66 \%$ were neurologically normal at a median follow-up of 4.4 years. In 2003 , Fullerton et al. ${ }^{11}$ reported on the use of embolization in 27 patients with VGMs, which resulted in a $15 \%$ mortality rate during hospitalization, and $61 \%$ of the patients had no or mild developmental delay. In 2006, Gupta et al. ${ }^{19}$ reported on 13 patients with VGMs and 2 with VGADs. Embolization resulted in complete obliteration of the fistula in $66 \%$ of the cases (10 of 15 patients) and a mortality rate of $20 \%$ (3 patients) due to intracranial hemorrhage and meningitis. Follow-up at an average of 6.8 years revealed stable cognitive functions and improvements of delayed milestones.

Most recently, Lasjaunias et al. ${ }^{31}$ reported on a series of 233 patients who underwent endovascular embolization via a transfemoral approach. The general mortality rate was $10.6 \%$ (23 of 216 patients), whereas that for neonates was $52 \%$ (12 of 23 patients). However, the authors mentioned that only 3 deaths were due to the embolization procedures and that most neonatal deaths represented cases in which a score of $<8$ would not have warranted intervention. One hundred forty-three (74\%) of the 193 survivors were neurologically normal on follow-up. Angiographic studies confirmed 90 to $100 \%$ occlusion in $55 \%$ of patients and showed that some small persistent shunts can be well tolerated and may resolve spontaneously over time.

\section{Conclusions}

A VGM is a congenital vascular malformation consisting of multiple arteriovenous shunts draining into the median prosencephalic vein of Markowski, which is not actually the vein of Galen itself, but rather a persistent embryonic structure that precedes the vein of Galen. Classically, VGM presents in the neonatal period with cardiac output failure and in severe cases with diffuse brain destruction referred to as melting brain. In infancy the main findings are hydrocephalus and developmental delays, and in childhood intracerebral and subarachnoid hemorrhage. While the prognosis of VGM has been especially grim in the past, with the mortality rate approaching $100 \%$ in some cases, many studies have shown that endovascular embolization is highly effective in improving the neurological outcome of patients with VGM. The timing of embolization is critical for the best possible outcome, with emergency treatment of neonates suffering acute heart and renal failure and delayed treatment if not suffering acute distress, optimally at 5-6 months of age. When CSF ventricular shunting is necessary to alleviate hydrocephalus, it should be performed after the embolization procedure. ${ }^{2}$ The use of a 21-point scale score based on cardiac, cerebral, hepatic, respiratory, and renal function can be used to guide therapeutic decisions. ${ }^{31}$ Endovascular therapy together with a comprehensive, multidisciplinary approach in the intensive care units has now emerged as the optimal approach for improving the poor prognosis of patients with VGM.

\section{Disclaimer}

The authors report no conflict of interest concerning the mate- rials or methods used in this study or the findings specified in this paper.

\section{References}

1. Alberico RA, Barnes P, Robertson RL, Burrows PE: Helical $\mathrm{CT}$ angiography: dynamic cerebrovascular imaging in children. AJNR Am J Neuroradiol 20:328-334, 1999

2. Alvarez H, Garcia Monaco R, Rodesch G, Sachet M, Krings T, Lasjaunias P: Vein of Galen aneurysmal malformations. Neuroimaging Clin N Am 17:189-206, 2007

3. Berenstein A, Lasjaunias P: Arteriovenous fistulas of the brain, in Surgical Neuroangiography. Endovascular Treatment of Cerebral Lesions. Berlin: Springer-Verlag, 1992, p 267

4. Brunelle F: Brain vascular malformations in the fetus: diagnosis and prognosis. Childs Nerv Syst 19:524-528, 2003

5. Casasco A, Lylyk P, Hodes JE, Kohan G, Aymard A, Merland JJ: Percutaneous transvenous catheterization and embolization of vein of Galen aneurysms. Neurosurgery 28:260-266, 1991

6. Chevret L, Durand P, Alvarez H, Lambert V, Caeymax L, Rodesch G, et al: Severe cardiac failure in newborns with VGAM. Prognosis significance of hemodynamic parameters in neonates presenting with severe heart failure owing to vein of Galen arteriovenous malformation. Intensive Care Med 28:1126-1130, 2002

7. Deeg KH, Scharf J: Colour Doppler imaging of arteriovenous malformation of the vein of Galen in a newborn. Neuroradiology 32:60-63, 1990

8. Dowd CF, Halbach VV, Barnwell SL, Higashida RT, Edwards MS, Hieshima GB: Transfemoral venous embolization of vein of Galen malformations. AJNR Am J Neuroradiol 11:643648,1990

9. Frawley GP, Dargaville PA, Mitchell PJ, Tress BM, Loughnan P: Clinical course and medical management of neonates with severe cardiac failure related to vein of Galen malformation. Arch Dis Child Fetal Neonatal Ed 87:F144-F149, 2002

10. Friedman DM, Verma R, Madrid M, Wisoff JH, Berenstein A: Recent improvement in outcome using transcatheter embolization techniques for neonatal aneurysmal malformations of the vein of Galen. Pediatrics 91:583-586, 1993

11. Fullerton HJ, Aminoff AR, Ferriero DM, Gupta N, Dowd CF: Neurodevelopmental outcome after endovascular treatment of vein of Galen malformations. Neurology 61:1386-1390, 2003

12. Gailloud P, O'Riordan DP, Burger I, Lehmann CU: Confirmation of communication between deep venous drainage and the vein of Galen after treatment of a vein of Galen aneurysmal malformation in an infant presenting with severe pulmonary hypertension. AJNR Am J Neuroradiol 27:317-320, 2006

13. Gailloud P, O'Riordan DP, Burger I, Levrier O, Jallo G, Tamargo RJ, et al: Diagnosis and management of vein of Galen aneurysmal malformations. J Perinatol 25:542-551, 2005

14. Garcia-Monaco R, Lasjaunias P, Berenstein A: Therapeutic management of vein of Galen aneurysmal malformations, in Vinuela F, Halbach VV, Dion JE (eds): Interventional Neuroradiology: Endovascular Therapy of the Central Nervous System. New York: Raven Press, 1992, p 113

15. Garcia-Monaco R, De Victor D, Mann C, Hannedouche A, Terbrugge K, Lasjaunias P: Congestive cardiac manifestations from cerebrocranial arteriovenous shunts. Endovascular management in 30 children. Childs Nerv Syst 7:48-52, 1991

16. Gatscher S, Brew S, Banks T, Simcock C, Sullivan Y, Crockett J: Multislice spiral computed tomography for pediatric intracranial vascular pathophysiologies. J Neurosurg 107:203208, 2007

17. Gold A, Ransohoff J, Carter S: Vein of Galen malformation. Acta Neurol Scand Suppl 40 (11 Suppl):1-31, 1964

18. Gulati S, Kalra V: An uncommon variety of vein of Galen malformation. Indian Pediatr 39:307-308, 2002 


\section{Vein of Galen malformations}

19. Gupta AK, Rao VR, Varma DR, Kapilamoorthy TR, Kesavadas C, Krishnamoorthy T, et al: Evaluation, management, and long-term follow up of vein of Galen malformations. J Neurosurg 105:26-33, 2006

20. Gupta AK, Varma DR: Vein of Galen malformations: review. Neurol India 52:43-53, 2004

21. Hoffman HJ, Chuang S, Hendrick EB, Humphreys RP: Aneurysms of the vein of Galen. Experience at the Hospital for Sick Children, Toronto. J Neurosurg 57:316-322, 1982

22. Jankowitz BT, Vora N, Jovin T, Horowitz M: Treatment of pediatric intracranial vascular malformations using Onyx-18. J Neurosurg Pediatr 2:171-176, 2008

23. Jones BV, Ball WS, Tomsick TA, Millard J, Crone KR: Vein of Galen aneurysmal malformation: diagnosis and treatment of 13 children with extended clinical follow-up. AJNR Am J Neuroradiol 23:1717-1724, 2002

24. Jordan L, Raymond G, Lin D, Gailloud P: CT angiography in a newborn child with hydranencephaly. J Perinatol 24:565567,2004

25. Kothari SS, Naik N, Juneja R, Saxena A: Aneurysm of the vein of Galen in neonates: report of four cases. Indian Heart J 53:499-502, 2001

26. Kurihara N, Tokieda K, Ikeda K, Mori K, Hokuto I, Nishimura $\mathrm{O}$, et al: Prenatal MR findings in a case of aneurysm of the vein of Galen. Pediatr Radiol 31:160-162, 2001

27. Lasjaunias P: Vein of Galen aneurysmal malformation, in Vascular Diseases in Neonates, Infants and Children. Berlin-Heidelberg: Springer-Verlag, 1997, p 67

28. Lasjaunias P, Alvarez H, Rodesch G, Garcia-Monaco R, ter Brugge KG, Burrows P, et al: Aneurysmal malformations of the vein of Galen: follow-up of 120 children treated between 1984 and 1994. Intervent Neuroradiol 2:15-26, 1996

29. Lasjaunias P, Garcia-Monaco R, Rodesch G, Ter Brugge K, Zerah M, Tardieu M, et al: Vein of Galen malformation. Endovascular management of 43 cases. Childs Nerv Syst 7:360367,1991

30. Lasjaunias P, Ter Brugge K, Lopez Ibor L, Chiu M, Flodmark $\mathrm{O}$, Chuang S, et al: The role of dural anomalies in vein of Galen aneurysms: report of six cases and review of the literature. AJNR Am J Neuroradiol 8:185-192, 1987

31. Lasjaunias PL, Chng SM, Sachet M, Alvarez H, Rodesch G, Garcia-Monaco R: The management of vein of Galen aneurysmal malformations. Neurosurg 59:S184-S94, 2006

32. Long DM, Seljeskog EL, Chou SN, French LA: Giant arteriovenous malformations of infancy and childhood. J Neurosurg 40:304-312, 1974

33. Mickle JP, Mericle RA, Burry MV, Williams LS: Vein of Galen malformations, in Winn RH: Youmans Neurological Surgery, Vol 3. Philadelphia: Saunders, 2004, p 3433

34. Mickle JP, Quisling RG: The transtorcular embolization of vein of Galen aneurysms. J Neurosurg 64:731-735, 1986

35. Mitchell PJ, Rosenfeld JV, Dargaville P, Loughnan P, Ditchfield MR, Frawley G, et al: Endovascular management of vein of Galen aneurysmal malformations presenting in the neonatal period. AJNR Am J Neuroradiol 22:1403-1409, 2001
36. Muneuchi J, Joo K, Higashiyama K, Mizushima A: Multislice spiral computed tomography in a neonate with vein of Galen aneurysmal malformation. J Pediatr 150:323-e1, 2007

37. Nangiana J, Lim M, Silva R, Guzman R, Chang S: Vein of Galen malformations-part I: epidemiology, clinical presentation, and radiologic evaluation. Contemp Neurosurg 30:2008

38. Nangiana J, Lim M, Silva R, Guzman R, Chang S: Vein of Galen malformations-part II: management. Contemp Neurosurg 30:2008

39. Nikas DC, Proctor MR, Scott RM: Spontaneous thrombosis of vein of Galen aneurysmal malformation. Pediatr Neurosurg 31:33-39, 1999

40. Nuutila M, Saisto T: Prenatal diagnosis of vein of Galen malformation: a multidisciplinary challenge. Am J Perinatol 25: 225-227, 2008

41. Pellegrino PA, Milanesi O, Saia OS, Carollo C: Congestive heart failure secondary to cerebral arterio-venous fistula. Childs Nerv Syst 3:141-144, 1987

42. Raybaud CA: Development of the arterial supply to the brain tissue, in Lasjaunias P, Berenstein A: Surgical Neuroangiography, Vol 3. New York: Springer-Verlag, 1990

43. Raybaud CA, Strother CM, Hald JK: Aneurysms of the vein of Galen: embryonic considerations and anatomical features relating to the pathogenesis of the malformation. Neuroradiology 31:109-128, 1989

44. Rodesch G, Hui F, Alvarez H, Tanaka A, Lasjaunias P: Prognosis of antenatally diagnosed vein of Galen aneurysmal malformations. Childs Nerv Syst 10:79-83, 1994

45. Ruano R, Benachi A, Aubry MC, Brunelle F, Dumez Y, Dommergues M: Perinatal three-dimensional color power Doppler ultrasonography of vein of Galen aneurysms. J Ultrasound Med 22:1357-1362, 2003

46. Taylor GA: Intracranial venous system in the newborn: evaluation of normal anatomy and flow characteristics with color Doppler US. Radiology 183:449-452, 1992

47. terBrugge KG: Vein of Galen management in neonatal period. AJNR Am J Neuroradiol 22:1236-1237, 2001

48. Vintzileos AM, Eisenfeld LI, Campbell WA, Herson VC, DiLeo PE, Chameides L: Prenatal ultrasonic diagnosis of arteriovenous malformation of the vein of Galen. Am J Perinatol 3:209-211, 1986

49. Yaşargil MG: Microneurosurgery. New York: Thieme, 1988

50. Zerah M, Garcia-Monaco R, Rodesch G, Terbrugge K, Tardieu M, de Victor D, et al: Hydrodynamics in vein of Galen malformations. Childs Nerv Syst 8:111-117, 1992

Manuscript submitted July 16, 2009.

Accepted August 26, 2009.

Address correspondence to: Raphael Guzman, M.D., Division of Pediatric Neurosurgery, Lucile Packard Children's Hospital, Stanford University School of Medicine, 300 Pasteur Drive, R211, Stanford, California 94305-5327. email: raphaelg@stanford.edu. 